\title{
Applied aspects of e-commerce system modeling
}

\author{
Olga Syniavska ${ }^{1}$ \\ ${ }^{1}$ Economic Cybernetics Department, Sumy State University
}

\section{Article Info}

Received Jan 19, 2019

\section{Keyword:}

Dynamic system

E-commerce

Internet economy

On-line segment

Queuing systems

\begin{abstract}
For every business today, the most important tasks are the timely informing of the target audience and the ability to sell the product or service as quickly as possible. Because of that reasons the e-commerce system has received such an extension, since such an approach allows simultaneous fulfillment of these and other tasks, control over realization of marketing tasks and make sales as effective as possible. Every year a large number of real (physical) business goes into on-line sphere. So, it is important to analyze the main principles of functioning of the company in the e-commerce sphere. Article is devoted to assessing the effectiveness of the company, which starts in the segment of ecommerce. When searching for the most rational route the average number of orders for the products, the average execution time, the average number of orders in the queue, as well as potential business, sales revenue product, investment and operational costs were taken into account. As a result, a mathematical model in a form of a system of three differential equations using the elements of queuing systems theory is presented. It allows to evaluate the expediency and efficiency of the transition of the enterprise from the real sector to the e-commerce system.
\end{abstract}

\section{Corresponding Author:}

Economic Cybernetics Department,

Sumy State University,

57 Petropavlivska, Sumy 40000, Ukraine.

Email: o.syniavska@uabs.sumdu.edu.ua

\section{Introduction}

One of the weightiest changes that the modern business world is currently experiencing is the rapid development and implementation of e-commerce. Every day more and more enterprises in different countries of the world are introducing e-commerce tools into their operations that allow them to attract new customers and, consequently, increase profits [2]. Every year, from $30 \%$ to $70 \%$ of business in any country (regardless of its level of development) goes into on-line [7]. Taking into account the progressive development of Web and Internet technologies, e-commerce is rapidly gaining a volume on a global scale and is formed as a separate branch of the economy.

In Fig. 1 retail e-commerce sales worldwide from 2014 to 2021 are presented [18].

In 2017, retail e-commerce sales worldwide amounted to 2.3 trillion US dollars and e-retail revenues are projected to grow to 4.88 trillion US dollars in 2021. Online shopping became one of the most popular online activities worldwide [13, 18].

From the moment the Internet penetrates deeper and deeper into everyday life, the concept of e-commerce becomes ever more relevant.

Thus, the explanation of the concept of "e-commerce" actively began in the late 1990s - early 2000s. The authors divided into two camps:

- the former believed that e-commerce can be defined as the interaction between communication online systems, different data management systems and tools for providing security of these systems, through which commercial information about products or services is exchanged [6]; 
- those, supporters of more modern approaches, define e-commerce only as conducting operations for buying and selling goods on the Internet [3].

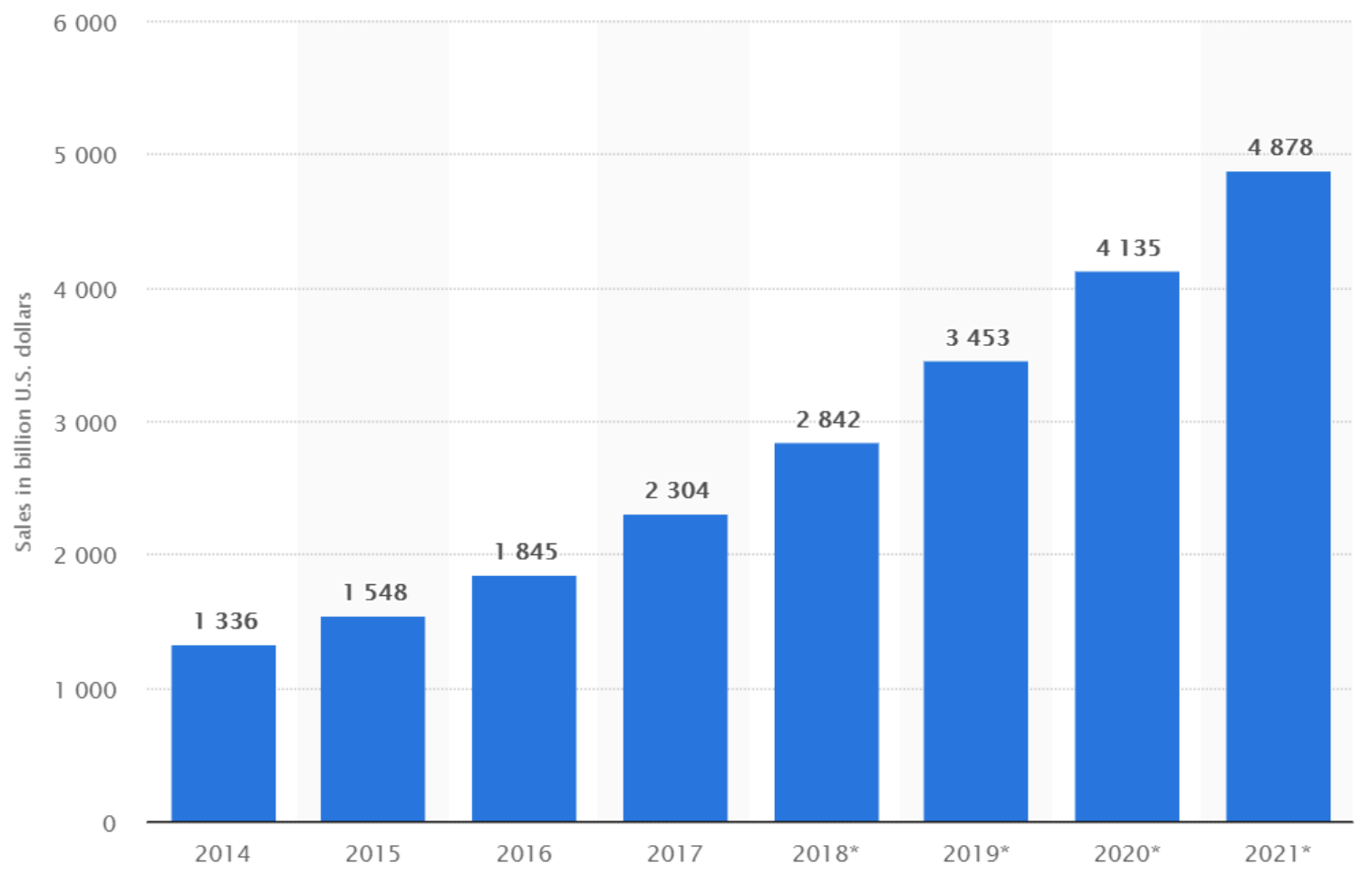

Figure 1. Retail e-commerce sales worldwide from 2014 to 2021 (in billion U.S. dollars), * - predicted values [18]

It should be noted that in the theoretical basics of e-commerce, this concept can be divided into the groups based on the type of economic relations and their cooperation between each other. The most common types are:

1) business-to-business (B2B) - the interaction of companies, enterprises, and so on; through various virtual B2B platforms, these entities have the opportunity to exchange information, find new partners, counterparties and conduct trading operations. Enterprises can also, through appropriate services, provide themselves with various accompanying services, purchase equipment, etc. [10];

2) business-to-consumer (B2C) - the type with which the concept of "electronic commerce" is often identified; provides interrelation of various companies and suppliers of goods and services with end users on the Internet;

3) consumer-to-consumer ( $\mathrm{C} 2 \mathrm{C})$ - provides interaction between the end users of Internet services (for example, online auctions, file sharing protocols, etc.) [14];

4) business-to-government (B2G) - the interaction of companies and enterprises with state administrative bodies. This system is becoming increasingly active in recent times. For example, the most rapid trend is the purchase of goods and services by governments of different countries and the leadership of international organizations on the Internet. In turn, commercial organizations have the opportunity to send their proposals and thus conduct a dialogue with the authorities [9];

5) consumer-to-government $(\mathrm{C} 2 \mathrm{G})$ - the direction in which all settlements with the state, which individuals and legal entities can implement in state structures, are in the online form. Today, such "digitalization" of relations between the government and citizens of the state is being introduced in Ukraine (online ordering of passports, obtaining extracts from the cadastre, registration of documents, etc.) [16]

6) mobile commerce (m-commerce) - buying and selling goods and services, exchanging information, making payments, etc. through wireless portable devices, such as mobile phones, smartphones, laptops and tablets, etc. These wireless devices interact with computer networks, having the ability to conduct certain operations on the Internet [4]. 
At the moment, the largest share of operations on the Internet is occupied by B2C. Although, this year there is a tendency to a rapid increase in the share of B2B companies moving to the e-commerce system.

Thus, it is worth paying special attention to assessing the effectiveness of the transition of the enterprise from the real sector to the e-commerce model.

Thus, this paper is devoted to the analysis of the theoretical foundations of the activities of e-commerce companies, the principles of customer service in the online sphere, as well as the development of a mathematical model for analyzing the effectiveness of a company's operations when switching to an ecommerce model.

\section{Materials and methods}

Consider the principle of functioning of e-commerce systems. Simplified, the processing of customer requests in an e-commerce system can be compared with a queuing system.

Queuing systems are those at which requests for service arrive at random times, while incoming requests are serviced using the service channels available to the system.

From the standpoint of queuing process modeling, situations when queues of requests (requirements) for service are formed, arise as follows: having entered the queuing system, the request joins the queue of other (previously received) requests. The service channel selects a requirement from those in the queue in order to start its service. After completion of the procedure for servicing the next request, the service channel proceeds to service the next request, if any, in the waiting unit.

The cycle of functioning of a queuing system of this kind is repeated many times during the entire period of operation of the serving system. It is assumed that the transition of the system to service the next request after the completion of the maintenance of the previous request occurs instantly, random moments of time.

The main components of a queuing system of any kind are:

- input flow of incoming requests or requests for service;

- discipline of the queue;

- maintenance mechanism [5].

Input flow of requirements. To describe the input flow, it is necessary to set a probabilistic law that determines the sequence of the moments of arrival of requirements for servicing and to indicate the number of such requirements in each regular arrival. At the same time, as a rule, the term "probabilistic distribution of the moments of receipt of requirements" is used. Here both single and group requirements can be received (requirements are received by groups in the system). In the latter case, a queuing system with parallel-group services takes place.

Discipline of the queue is an important component of the queuing system; it defines the principle in accordance with which the requirements coming to the input of the service system are connected from the queue to the service procedure. The most frequently used disciplines are queues, defined by the following rules:

- first come - first served;

- came last - served first;

- random selection of requests;

- selection of requests by priority;

- limiting the waiting time for the service to occur (there is a queue with a limited waiting time for the service, which is associated with the concept of "allowable queue length").

The maintenance mechanism is determined by the characteristics of the maintenance procedure itself and the structure of the queuing system. The characteristics of the maintenance procedure include: the duration of the maintenance procedure and the number of requirements that are satisfied as a result of each such procedure. For an analytical description of the characteristics of the service procedure, they use the term "probability distribution of the service time of requirements".

It should be noted that the time required to service an application depends on the nature of the application itself or the client's requirements and on the state and capabilities of the queuing system. In some cases, it is also necessary to take into account the probability of the output of the servicing device after a certain limited time interval.

The structure of the servicing system is determined by the number and mutual arrangement of the service channels (mechanisms, instruments, etc.). First of all, it should be emphasized that the queuing system can 
have more than one service channel; the system of this kind is capable of servicing several requirements simultaneously. In this case, all service channels offer the same services, and, therefore, it can be argued that there is a parallel service.

The service system may consist of several different types of service channels through which each serviceable demand must pass, i.e. in the service system the procedures for servicing requirements are implemented sequentially. The maintenance mechanism determines the characteristics of the outgoing (served) flow of requirements.

The subject of queuing theory is to establish the relationship between the factors that determine the functional capabilities of the queuing system, and the efficiency of its operation. In most cases, all parameters that describe queuing systems are random variables or functions; therefore, these systems are referred to as stochastic systems.

The random nature of the flow of requests (requirements), as well as, in general, the duration of service, leads to the fact that a random process occurs in the queuing system. By the nature of the random process occurring in the queuing system (QS), Markov and non-Markov systems are distinguished. In Markov systems, the incoming stream of requirements and the outgoing stream of served requests (applications) are Poisson. Poisson flows make it easy to describe and build a mathematical model of a queuing system.

Regardless of the nature of the process taking place in the queuing system, there are two main types of QS:

- systems with refusals, in which the requests that entered the system at the moment when all channels are busy, receives a refusal and immediately enters the queue;

- systems with waiting (queue), in which the requests, received at the moment when all the service channels are busy, becomes in the queue and waits until one of the channels is free. Queuing systems with waiting are divided into systems with limited waiting and systems with unlimited waiting [8].

All queuing systems are distinguished by the number of service channels:

- single channel systems;

- multichannel systems.

Multichannel queuing systems are the most common with e-commerce systems. Therefore, we consider the main theoretical aspects of the modeling of multinational QS.

The process of queuing service described by the model with $\mathrm{n}$ serving channels (where $n>1$ ) is characterized by the intensity of the input stream $\lambda$, while no more than $\mathrm{n}$ clients (requests) can be serviced in parallel. The average duration of service for one application is equal $1 / \lambda$. Input and output flows are Poisson. The operation mode of one or another serving channel does not affect the operation mode of other service channels of the system, and the duration of the maintenance procedure by each channel is a random variable with an exponential distribution law. The goal of using $\mathrm{n}$ parallel connected service channels is to increase (as compared to a single channel system) the speed of servicing requirements by servicing $\mathrm{n}$ clients at the same time. The intensity of the service flow is equal to $\mu$, therefore, the state diagram of a multi-channel queuing system with failures is presented in Fig. 2 [11].

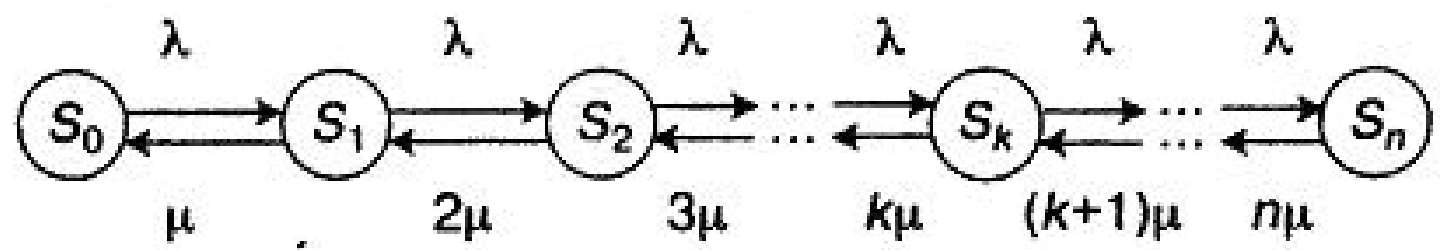

Figure 2. State diagram of multichannel QS with failures

The states of the QS have the following interpretation:

- $S_{0}$ - all channels are free;

- $S_{1}$ - one channel is occupied, the rest are free;

- $S_{k}$ - exactly $k$ channels are occupied, the rest are free;

- $S_{n}$ - all $n$ channels are occupied.

Kolmogorov equations for the probabilities of states of the system $P_{0}, \ldots, P_{k}, \ldots P_{n}$ will have the following form [15]: 


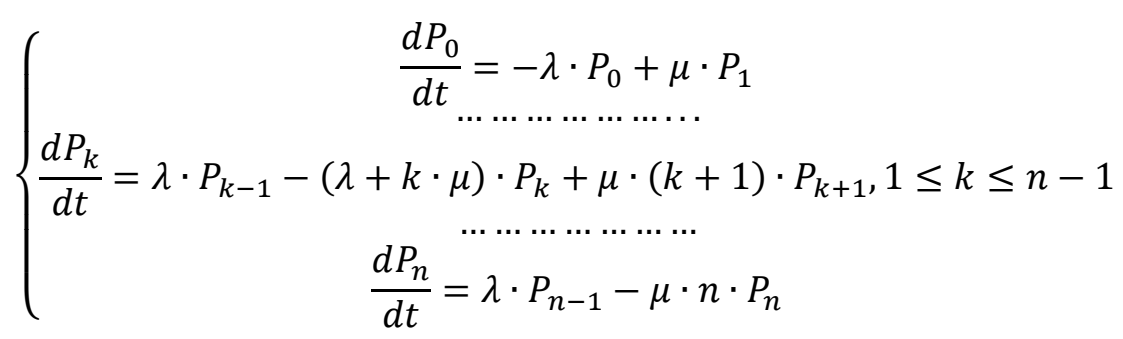

The initial conditions for solving the system are the following: $P_{0}(0)=1, P_{1}(0)=P_{2}(0)=\ldots=P_{k}(0)=\ldots=P_{1}(0)$ $=0$.

The stationary solution of the system has the form:

$$
\left\{\begin{array}{c}
P_{k}=\frac{\frac{\psi^{k}}{k !}}{\sum_{k=0}^{n} \frac{\psi^{k}}{k !}}=\frac{\psi^{k}}{k !} \cdot P_{0}, k=0 \ldots n \\
P_{0}=\frac{1}{\sum_{k=0}^{n} \frac{\psi^{k}}{k !}}, k=0 \ldots n
\end{array}\right.
$$

where $\psi=\frac{\lambda}{\mu}$.

Formulas (2) for calculating probabilities $P_{k}$ are called Erlang formulas.

We define the probabilistic characteristics of the functioning of the multichannel QS with failures in the stationary mode [19]:

1) failure probability:

$$
P_{\text {fail }}=P_{n}=\frac{\psi^{n}}{n !} \cdot P_{0}
$$

as the application receives a refusal if it arrives at the moment when all $n$ channels are occupied. The value $P_{\text {fail }}$ characterizes the completeness of the service of the incoming flow;

2) the probability that the request will be accepted for service (it's also the relative capacity of the system $q$ ) complements $P_{\text {fail }}$ to one:

$$
q=1-P_{\text {fail }}=1-\frac{\psi^{n}}{n !} \cdot P_{0}
$$

3) absolute bandwidth:

$$
A=\lambda \cdot q=\lambda \cdot\left(1-P_{\text {fail }}\right)
$$

4) average number of service channels:

$$
\bar{k}=\sum_{k=1}^{n} k \cdot P_{k}=\psi \cdot\left(1-P_{\text {fail }}\right)
$$

The value $\bar{k}$ characterizes the degree of loading of the QS.

In the case of multichannel QS with the expectation we'll have the following: input and output flows are Poisson with intensities $\lambda$ and $\mu$, respectively; no more than $S$ clients can be serviced in parallel. The system has $S$ service channels. The average duration of service for one client is equal $\frac{1}{\mu}$. 
In the steady state of the operation of a multichannel QS with a wait and unlimited queue, QS can be described using a system of algebraic equations:

$$
\begin{gathered}
0=\lambda \cdot P_{n-1}-(\lambda+n \cdot \mu) \cdot P_{n}+(n+1) \cdot \mu \cdot P_{n+1}, \quad \text { if } 1 \leq n \leq S \\
0=\lambda \cdot P_{n-1}-(\lambda+S \cdot \mu) \cdot P_{n}+S \cdot \mu \cdot P_{n+1}, \quad \text { if } n \geq S
\end{gathered}
$$

The solution of the system of equations (7) is

$$
\left\{\begin{array}{l}
P_{n}=\frac{\psi^{n}}{n !} \cdot P_{0}, \quad \text { if } 1 \leq n \leq S \\
P_{n}=\frac{\psi^{n}}{S ! S^{n-S}} \cdot P_{0}, \quad \text { if } n \geq S
\end{array}\right.
$$

where

$$
P_{0}=\left\{\sum_{n=0}^{S-1} \frac{\psi^{n}}{n !}+\frac{\psi^{S}}{S !\left[1-\frac{\psi}{S}\right]}\right\}^{-1}
$$

The decision will be valid if the following condition is true: $\frac{\lambda}{S \cdot \mu}<1$.

The probabilistic characteristics of functioning in the stationary mode of a multichannel QS with wait and unlimited queue are determined by the following formulas [12]:

1) the probability that there are $n$ clients in the system on a service is determined by the formula (8);

2) the average number of customers in the service queue:

$$
L_{q}=\left[\frac{S \cdot \psi}{(S-\psi)^{2}}\right] \cdot P_{S}
$$

3) average number of clients in the system (service requests and in queues):

$$
L_{s}=L_{q}+\psi
$$

4) the average duration of the client's stay (service requests) in the queue:

$$
W_{q}=\frac{L_{q}}{\lambda}
$$

5) the average duration of the client's stay in the system

$$
W_{S}=W_{q}+\frac{1}{\mu}
$$

\section{Results and discussion}

As mentioned above, every year a huge part of the real business goes online. Enterprises daily estimate the costs and profits from the implantation of e-commerce systems into their activities.

In general, it is important to assess the feasibility of the entry of a traditional enterprise into the e-commerce segment. To solve this problem, it is necessary to simulate the virtual enterprise in the information and economic environment, as well as the analysis of the effectiveness of the probable transition of the enterprise from the traditional to the virtual type.

Based on the considered theoretical foundations of QS, we'll evaluate the feasibility of transitioning a real enterprise to e-commerce technologies (on an example of a company that sells certain products).

The given input parameters are:

- number of virtual work places $n$; 
- the average number of orders for goods received on the Internet for the average execution time of the order:

$$
z=\frac{\alpha}{\beta}=\alpha \cdot \bar{t}_{e x}
$$

where $\alpha$ - frequency of orders input;

$\bar{t}_{e x}$ - average normative time of the task execution by the worker $\left(\beta=\frac{1}{\bar{t}_{e x}}\right.$ - the intensity of the order execution).

As characteristics of the effectiveness of the virtual structure, consider the following:

- the potential of the enterprise $E=a \cdot\left(1-V_{z}\right)$, where $V_{z}$ - the probability of refusal to execute the order;

- average order execution time $\bar{t}_{\text {ex.o }}=\frac{\bar{z}}{\alpha}, \bar{z}=\bar{r}+\bar{o}$ - average number of orders;

- the average number of occupied virtual jobs $\bar{r}=v\left(1-v_{n+m}\right)$;

- average number of orders in the queue $\bar{o}=\frac{v^{n+1}}{n n !} V_{o} \frac{1-(m+1) x^{m}+m x^{m+1}}{(1-x)^{2}}$, where $m$ - the number of workplaces in the queue, $v=\frac{\alpha}{\beta}, x=\frac{v}{n}<1$.

Comparing, on other equal terms, the average time of execution of an order in the conditions of organization of virtual work and in terms of organization of work according to the traditional principle, we'll have less number, which is decisive when choosing the most effective organizational structure of the enterprise.

To evaluate the financial state of a virtual innovation enterprise, it is expedient to use a dynamic system. This approach is based on the theory of self-organization [1]. The dynamic variable is the amount of cash working capital $M$. Equation of the balance is as follows:

$$
\frac{d M}{d t}=W-\frac{M}{\tau_{1}}+M_{e x} \delta\left(t-t_{1}\right)-\frac{M_{e x}}{\tau_{c r}}-K
$$

where $W$ - income from sales;

$\frac{M}{\tau_{1}}$ - production costs;

$\tau_{S}$ - time of turnover;

$M_{\text {ex }}$ - investments;

$K$ - capital investments of own funds.

Income $W$ equals the quantity of $Q_{r}$ product sold at a certain price:

$$
W=Q_{r} p
$$

$Q$ quantity of goods sold depends on the average number of orders and the intensity of the order processing $\beta$. It is also necessary taking into account capital investments of own funds:

$$
\frac{d K x}{d t}=1-M K \Rightarrow \frac{d K x}{d t}=M_{e x}+Q P-M \cdot K x
$$

Then, in the form of a dynamic variable, consider the volume of external borrowing:

$$
\frac{d M_{e x}}{d t}=E \cdot M
$$

where $E$ - attractiveness factor.

Also,

$$
Q=\frac{v^{n+1}}{n n !} \cdot \frac{1-(m+1) x^{m}+m x^{m+1}}{(1-x)^{2}}
$$


Finally, based on theoretical bases of queuing systems, the theory of self-organization and points discussed above we receive the mathematical model of the activity and assessment of the efficiency of the e-commerce enterprise:

$$
\left\{\begin{array}{c}
\frac{d M}{d t}=\frac{v^{n+1}}{n n !} \cdot \frac{1-(m+1) x^{m}+m x^{m+1}}{(1-x)^{2}} \cdot P-\frac{M}{t}-\frac{M_{e x}}{t^{2}} \\
\frac{d K x}{d t}=M_{e x}+\frac{v^{n+1}}{n n !} \cdot \frac{1-(m+1) x^{m}+m x^{m+1}}{(1-x)^{2}} \cdot P-M \cdot K x \\
\frac{d M_{e x}}{d t}=a \cdot\left(1-V_{z}\right) \cdot M \cdot t^{z}
\end{array}\right.
$$

Taking into account the parameter $Q$, in the reduced form the model will be:

$$
\left\{\begin{array}{c}
\frac{d M}{d t}=Q \cdot P-\frac{M}{t}-\frac{M_{e x}}{t^{2}} \\
\frac{d K x}{d t}=M_{e x}+Q \cdot P-M \cdot K x \\
\frac{d M_{e x}}{d t}=a \cdot\left(1-V_{z}\right) \cdot M \cdot t^{Z}
\end{array}\right.
$$

The practical implementation of this model is performed using the MathCad tool. Setting the initial conditions, we calculate the necessary parameters, then we will calculate the system of differential equations. On the basis of solving the system of differential equations (20), we obtain a graph that clearly reflects the dynamics of the research parameters (Fig. 3).

$M(t)$ - the graph illustrates the increase in money circulation at the enterprise. It is logical that with attraction of funds it reflects the growing dynamics.

$K x(t)$ - graph illustrates the cost dynamics. It is quite natural that with the launch of the project of transition to a virtual type of trade, costs first increase, reach their maximum, then rapidly falling down and asymptotically close to a minimum. This may be explained by the fact that in the process of development the company's operations become more stable and efficient.

$\operatorname{Mex}(t)$ - graph illustrates the dynamics of investments. As you can see, the more we invest, the more rapidly the enterprise develops.

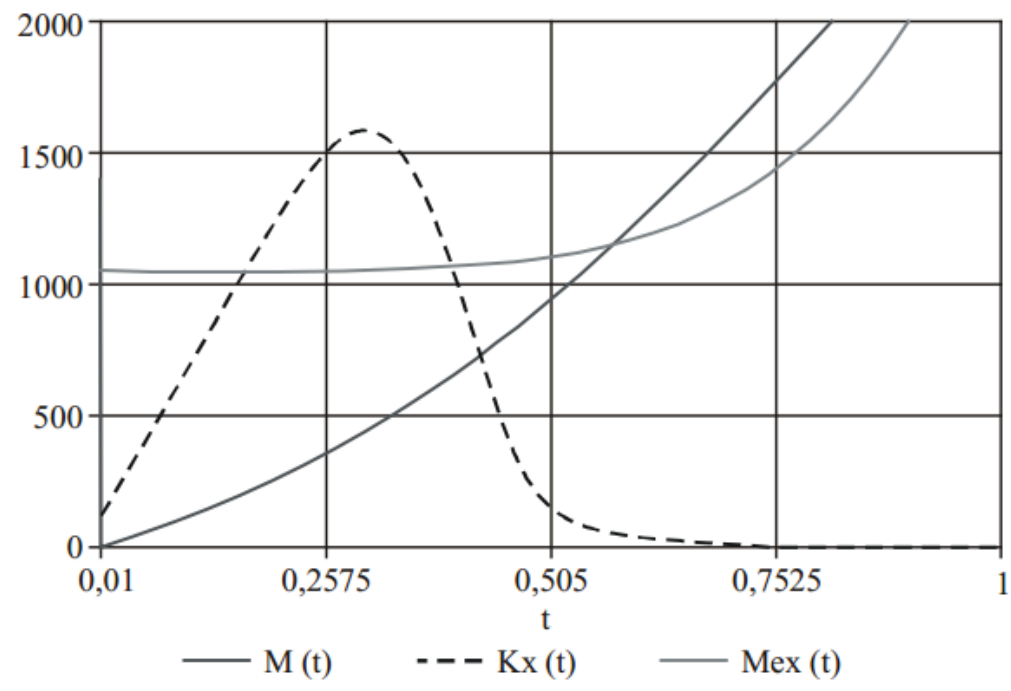

Figure 3. Dynamics of output indicators 


\section{Conclusion}

E-commerce is every day becoming more and more an integral part of the life of every person. Every day more and more enterprises are introducing e-commerce systems into their activities. $91 \%$ of Internet users carry out a purchase operation in an online environment. E-commerce allows to make the possibility of acquiring goods, receiving services, exchanging information, etc. without significant efforts for the end user. Even if the entity that offers its services has a rather specific product, it doesn't matter, the user who is interested in it will definitely be part of the network.

In this study, the activities of companies in the field of e-commerce are considered from the perspective of the theory of queuing systems. It is found that every online enterprise, in fact, is a multichannel QS with a wait and unlimited queue.

Based on the theoretical assumptions, the mathematical model of the activity and assessment of the efficiency of the e-commerce enterprise was developed. Analyzing the obtained results, it should be noted that it is quite obvious that the company is moving to the e-commerce segment. According to the constructed model, with the increase in investment, we observe the growth of money circulation and thus a gradual reduction of expenses.

Consequently, the identification of general principles for the formation of management procedures in the development of information technology and the construction of specific models for calculating the effectiveness of the existence of a virtual enterprise can achieve that such procedures become an effective, innovative tool in the activities of business entities.

$\begin{array}{ll}\text { Abbreviations } & \\ \text { B2B } & \text { Business-to-business } \\ \text { B2C } & \text { Business-to-consumer } \\ \text { B2G } & \text { Business-to-government } \\ \text { C2C } & \text { Consumer-to-consumer } \\ \text { C2G } & \text { Consumer-to-government } \\ \text { QS } & \text { Queuing system }\end{array}$

\section{References}

[1] Babenko, V., (2013). Formation of economic-mathematical model for process dynamics of innovative technologies management at agroindustrial enterprises. Actual Problems of Economics, 139(1): 182186.

[2] Babenko V.; Syniavska O., (2018). Analysis of the current state of development of electronic commerce market in Ukraine. Technology audit and production reserves, 5, 4(43): 40-45; DOI: https://doi.org/10.15587/2312-8372.2018.146341.

[3] Efendi, J.; Kinney, M., (2013). Marketing Supply Chain Using B2B Buy-Side-E-Commerce Systems: Does Adoption Impact Financial Performance?. Academy of Marketing Studies Journal, 17 (2): 73-81 (9 pages).

[4] Gallaugher, J., (2012). E-Commerce and the Undulating Distribution Channel. Communications of the ACM, 45 (7): 89-95; doi: 10.1145/514236.514240.

[5] Giambene, G., (2014). Queuing Theory and Telecommunications: Networks and Applications. Data Retrieved from https://books.google.com./books?id=

Cu8BAAAQBAJ\&pg=PA378\&dq=Theories+and+Applica tions+Related+to+Queuing+Systems+PDF\&hl=en\&sa $=$ X\&ei $=$ clSaVKrxCaTOygOL3YKoCw\&ved $=0$ CCgQ6AEwAA9.\#v=onepage \&q=Theories\%20and\%20Applications\%20Related\%20to\%20Queuing\% 20Systems\%20PDF\&f=false

[6] Kelly, K., (1998). New rules for the new economy, Penguin, New York.

[7] Melnichuk, O. S., (2014). Hlobal'ni tendentsiyi rozvytku elektronnoyi komertsiyi. Naukovi pratsi NDFI, 1 (66): 58-69.

[8] Nafees, A. (2007). Queuing Theory and its Application: Analysis of the Sales Checkout Operation in ICA Supermarket. Data Retrieved from http://www.statistics.du.se/essays/D07E.Nafees.pdf

[9] Nanehkaran, Y. (2013). An Introduction To Electronic Commerce. International Journal of Scientific \& Technology Research, 2 (4), 190-193. 
[10] Nemat, R. (2011). Taking a Look at Different Types of E-commerce. World Applied Programming, 1 (2), 100-104.

[11] Obzherin, Y. E. (2016). Semi-Markovian Model of Two-Line Queuing System with Losses. Intelligent Information Management, 8(2). 34-56.

[12] Oliynyk, V. (2015). Modeling of the optimal structure of insurance portfolio. Problems and Perspectives in Management, 2 (13), 230-234.

[13] Report From The Commission To The Council And The European Parliament. (2017). Retrieved from http://ec.europa.eu/competition/antitrust/sector_inquiry_final_report_en.pdf

[14] Roberts, M. L. \& Zahay, D. (2017). Internet Marketing: Integrating Online and Offline Strategies in a Digital Environment. Publisher: Cengage. researchgate.net. Retrieved from https://www.researchgate.net/publication/317692557_Internet_Marketing_Integrating_Online_and_Offl ine_Strategies_in_a_Digital_Environment_Fourth_Edition

[15] Sani, S. (2014) Mathematical Modeling in Heavy Traffic Queuing Systems. American Journal of Operations Research, 4 (6). 98-103. doi: 10.4236/ajor.2014.46033.

[16] Shirley, H., Smith, M. (2009). Impact of Internet Financial Reporting on Emerging Markets. Journal of International Business Research, 8 (2), 21-41.

[17] Sydorova, O. V. (2011). Regulirovaniye elektronnoy ekonomicheskoy deyatel'nosti v zarubezhnykh stranakh. Problemy sovremennoy ekonomiki, 2, 97-100.

[18] The Statistics Portal. Retrieved from https://www.statista.com/.

[19] Xavier, G, (2018). Using Poisson Modeling and Queuing Theory to Optimize Staffing and Decrease Patient Wait Time in the Emergency Department. Open Journal of Emergency Medicine, 6 (3), 30-35. doi: 10.4236/ojem.2018.63008. 